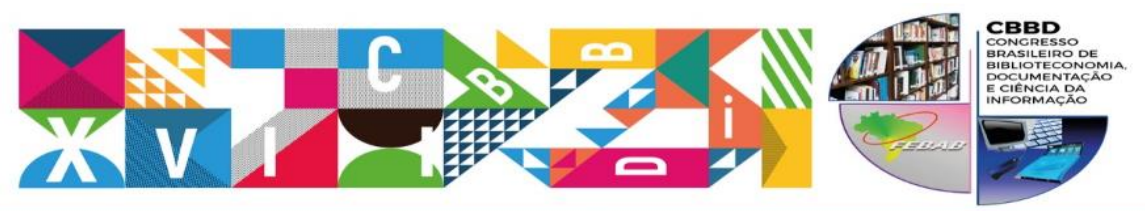

XXVII CONGRESSO BRASILEIRO DE BIBLIOTECONOMIA,

DOCUMENTAÇÃO E CIÊNCIA DA INFORMAÇÃOO

TEMA CENTRAL: Objetivos para o Desenvolvimento Sustentével das Naçóes Unidas:
como as bibliotecas podem contribuir com a implementação da Agenda 2030

\title{
Eixo 1 - Objetivos do Desenvolvimento Sustentável \\ COMPETÊNCIA EM INFORMAÇÃO PARA O DESENVOLVIMENTO SUSTENTÁVEL: uma experiência da Rede Ametista da CPRM - Serviço Geológico do Brasil
}

\section{Francisca Giovania Freire \\ Barros do Nascimento \\ Bibliotecária da CPRM Serviço \\ Geológico do Brasil, Biblioteca \\ Regional de Fortaleza \\ E-mail: giovania.freire@cprm.gov.br}

\section{Margareth Lopes de Moraes}

Bibliotecária da CPRM Serviço

Geológico do Brasil, Biblioteca

Central do Rio de Janeiro

E-mail:

margareth.moraes@cprm.gov.br

\section{Roberta Pereira da Silva de}

\section{Paula}

Bibliotecária da CPRM Serviço

Geológico do Brasil, Biblioteca

Central do Rio de Janeiro

E-mail: roberta.silva@cprm.gov.br

\section{RESUMO}

A CPRM - Serviço Geológico do Brasil tem como missão gerar e disseminar conhecimento geocientífico com excelência, contribuindo para a melhoria da qualidade de vida e do desenvolvimento sustentável do Brasil. Alinhado à essa missão, o Programa de Competência em Informação da Rede Ametista de Bibliotecas da CPRM, que possui 13 (treze) bibliotecas em todo o Brasil, foi elaborado para oferecer aos empregados da instituição e à comunidade em geral, o acesso à informação em Geociências e serviços que promovam a difusão do conhecimento e o bemestar da sociedade. 0 Programa de Competência em Informação foi idealizado em 5 (cinco) etapas denominadas Ações: Visitas Guiadas, Atendimento Individual, Treinamento Presencial em Grupos, Palestrantes Externos e Treinamento à Distância. Outras ações também foram desenvolvidas ao longo do Programa como a elaboração de boletins informativos, da Biblioteca Regional de Fortaleza, e o engajamento das bibliotecas no Projeto CPRM Sustentável. Após essas Ações, foi observado um aumento significativo na utilização dos espaços e serviços que as bibliotecas oferecem. Isto foi quantificado em cada Ação, sendo esses dados mensurados através de estatísticas. Conclui-se que o Programa deve continuar, sempre se aperfeiçoando, no seu propósito de colaborar na construção e na divulgação do conhecimento em Geociências para o bem-estar da sociedade brasileira.

Palavras-chave: Competência em Informação. Bibliotecas. Rede Ametista. Geociências. CPRM.

INFORMATION LITERACY FOR THE SUSTAINABLE DEVELOPMENT: an experience of Ametista Network of CPRM - Geological Survey of Brazil

\section{ABSTRACT}




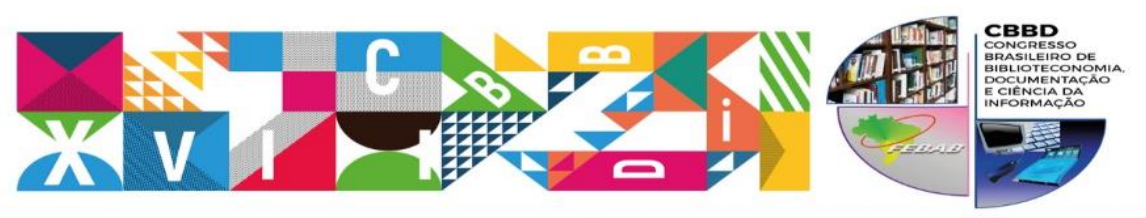

XXVII CONGRESSO BRASILEIRO DE BIBLIOTECONOMIA,

DOCUMENTAÇÃO E CIÊNCIA DA INFORMAÇÃO

TEMA CENTRAL: Objetivos para o Desenvolvimento Sustentável das Naçōes Unidas:
como as bibliotecas podem contribuir com a implementaçăo da Agenda 2030

CPRM - Geological Survey of Brazil has the mission of generating and disseminating geoscientific knowledge with excellence, contributing to the improvement of the quality of life and the sustainable development of Brazil. Lined up with this mission, the Information Literacy Program of CPRM's Libraries Amethyst Network, which has 13 (thirteen) libraries throughout Brazil, was designed to offer the institution's employees and the community in general access to information in Geosciences and services that promote the diffusion of knowledge and the well-being of society. The Information Literacy Program was conceived in 5 (five) stages called Actions: Guided Visits, Individual Assistance, In-Person Group Training, External Speakers and Distance Training. Other actions were also developed during the Program such as the preparation of newsletters of the Fortaleza Regional Library and the engagement of libraries in the Sustainable CPRM Project. After these Actions, the use of the spaces and services offered by the libraries increased significantly. This was quantified in each Action, these data being measured through statistics. In conclusion, the Program should continue, always improving, in its purpose of collaborating in the construction and dissemination of knowledge in Geosciences for the well-being of Brazilian society.

Key words: Information Literacy. Libraries. Ametista Network. Geosciences. CPRM.

\section{INTRODUÇÃO}

As bibliotecas, museus e outras unidades de informação têm procurado se adequar ao mundo globalizado fazendo com que políticas de acesso à informação se tornem mais visíveis à sociedade e, consequentemente, facilitando as tomadas de decisões para um melhor bem-estar no ambiente em que vivemos e proporcionando o desenvolvimento sustentável com uma integração entre economia, sociedade e meio ambiente.

Em consonância com o desenvolvimento sustentável, a CPRM - Serviço Geológico do Brasil tem como missão "gerar e disseminar conhecimento geocientífico com excelência, contribuindo para a melhoria da qualidade de vida e do desenvolvimento sustentável do Brasil". Consequentemente, a

Rede de Bibliotecas da CPRM, Rede Ametista, também participa dessa missão, integrando suas bibliotecas, promovendo a cooperação entre seus membros, otimizando o 


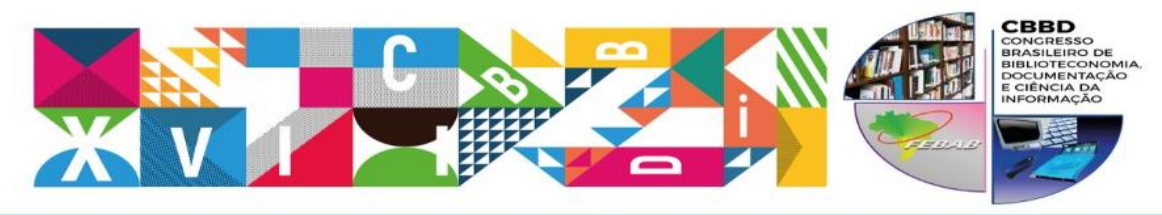

XXVII CONGRESSO BRASILEIRO DE BIBLIOTECONOMIA, DOCUMENTAÇÃOO E CIÊNCIA DA INFORMAÇĀO

TEMA CENTRAL: Objetivos para o Desenvolvimento Sustentável das Naçōes Unidas:
como as bibliotecas podem contribuir com a implementaçao da Agenda 2030

intercâmbio da informação geocientífica e ampliando o acesso à pesquisa com o objetivo de subsidiar a demanda informacional da sociedade.

\subsection{CPRM - Serviço Geológico do Brasil}

A CPRM é uma empresa pública vinculada ao Ministério de Minas e Energia. Iniciou suas atividades em janeiro de 1970. Ela realiza levantamentos geológicos, geofísicos, hidrogeológicos e análises químicas e minerais. Também avalia recursos minerais do Brasil com o objetivo de disponibilizar um banco de dados brasileiros e desenvolver pesquisa geológico-metalogenética em ambientes de reconhecida vocação mineral, como forma de atrair interesses e investimentos em pesquisa mineral.

Além dos recursos do continente, em parceria com o Ministério da Defesa, a CPRM atua na pesquisa dos recursos da plataforma continental jurídica brasileira. Presta-se, ainda, a fornecer subsídios para políticas públicas de arranjos produtivos locais e tem como foco principal de atuação, atualmente, os minerais não metálicos, especialmente insumos para a agricultura e materiais para construção.

Sendo depositária da memória geológica do Brasil, a CPRM dispõe de imenso acervo de dados e informações, em vários tipos de mídia, cujo gerenciamento e disponibilização constituem missão primordial da instituição. Nesse sentido, esta ação encerra atividades ligadas à pesquisa, desenvolvimento e aquisição de tecnologias que viabilizem e deem eficiência aos processos de suporte da informação geológica. Aqui se incluem desde os processos de aquisição de dados, passando por seu armazenamento e processamento, até a forma de disponibilizar os produtos finais à sociedade. (CPRM, 2017a).

\subsection{Rede Ametista da CPRM}




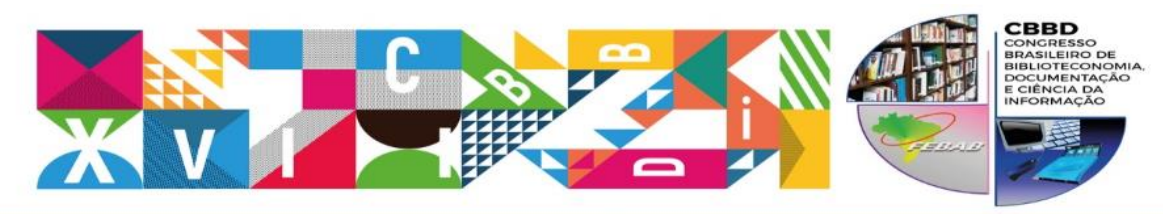

XXVII CONGRESSO BRASILEIRO DE BIBLIOTECONOMIA, DOCUMENTAÇÃO E CIÊNCIA DA INFORMAÇÃOO

TeMA cenrpal: Objetivos para o Desenvolvimento Sustentável das Naçōes Unidas:
como as bibliotecas podem contribuir com a implementação da Agenda 2030

A Rede de Bibliotecas da CPRM, denominada Rede Ametista, possui 13 (treze) bibliotecas em todo o Brasil localizadas nas respectivas unidades regionais da CPRM. Estas regionais são: Fortaleza, Recife, Salvador, Belém, Manaus, Porto Velho, Brasília, Goiânia, Teresina, Belo Horizonte, São Paulo, Porto Alegre e Rio de Janeiro, onde está situada a biblioteca central.

Congregando dados e informações impressas e digitais, a Rede Ametista promove o intercâmbio e a interação de um expressivo acervo em geociências, propiciando o atendimento adequado à demanda

de informações da sociedade. Além disso, proporciona acesso online às coleções de anais de congressos, de relatórios técnicos, boletins, mapas e fotografias aéreas pertinentes às geociências. Desde sua implantação, a Rede vem se ajustando às tendências tecnológicas, na expectativa de propiciar agilidade ao fornecimento da informação geocientífica e assim, fomentar a pesquisa sobre os conhecimentos geológico e hidrológico básicos necessários para o desenvolvimento sustentável do Brasil. Por isso, a Rede constitui um referencial de pesquisa para a comunidade geocientífica, expandindo o conhecimento gerado pela CPRM e fortalecendo parcerias nacionais e internacionais. (CPRM, 2017b).

Nesse contexto, foi gerado o Programa de Competência em Informação da Rede Ametista para promover as atividades já realizadas pelas unidades de informação, registrando e preservando suas iniciativas, assim como promover novas saberes e habilidades no uso da informação para seus usuários internos e externos.

\section{EMBASAMENTO TEÓRICO}

A competência em informação está no cerne do aprendizado ao longo da vida. Ela capacita as pessoas em todos os caminhos da vida para buscar, avaliar, usar e criar a informação de forma efetiva para atingir as metas pessoais, sociais, ocupacionais e educacionais. É um direito humano básico em um mundo digital e promove a inclusão social em todas as nações. (Faróis..., 2017).

A competência em informação seria a abrangência de diversas habilidades que os indivíduos necessitam para a autonomia de sua própria aprendizagem e construção do seu 


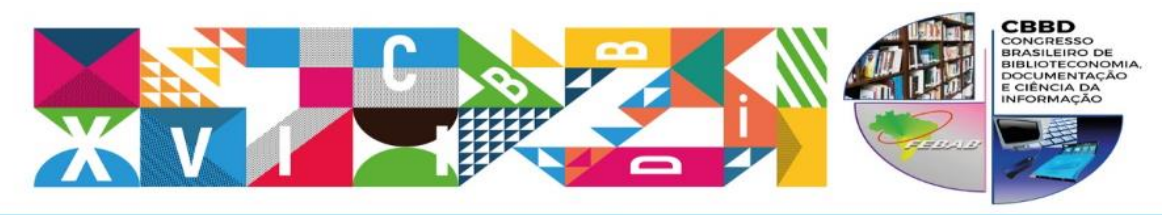

XXVII CONGRESSO BRASILEIRO DE BIBLIOTECONOMIA, DOCUMENTAÇÃO E CIÊNCIA DA INFORMAÇÃOO

TEMA CENTRAL: Objetivos para o Desenvolvimento Sustentável das Naçōes Unidas:
como as bibliotecas podem contribuir com a implementaçăo da Agenda 2030

conhecimento. Essas habilidades seriam identificar que a informação é importante para o seu contexto de atuação, saber localizar a informação e avaliá-la como pertinente e utilizá-la em sua vida.

Para Lau (2014) o termo "competência" implica em um grupo de habilidades para identificar uma necessidade de informação, assim como recuperar, avaliar, usar e reconstruir o conhecimento contido nas fontes de informação recuperadas. Desenvolver essas habilidades em informação descrevendo o processo de busca da informação e a competência para utilizá-la, torna a pessoa um aprendiz efetivo.

A competência em informação, torna-se uma ferramenta importante ao reconhecer e compartilhar a informação de forma eficiente e eficaz com a sociedade. De acordo com Dudziak (2003) "competência em informação é um conjunto de conhecimentos, habilidades e atitudes mobilizados para uma ação visando a resolução de problemas ou propostas para sua solução".

0 atual e complexo cenário tem nas bibliotecas e unidades de informação, estruturas capazes de promover, através dos atributos da competência em informação incorporados nas atividades de rotina das bibliotecas, o desenvolvimento sustentável e a melhor qualidade de vida na sociedade.

As bibliotecas e os bibliotecários, como participantes do processo de construção do conhecimento, possuem um papel fundamental na educação de usuários. Eles podem, inclusive, inserir o indivíduo na sociedade da informação como agente ativo e desenvolver sua cidadania. (SANTOS, 2008).

Nesse sentido, o Programa de Competência em Informação da Rede Ametista foi desenvolvido para atuar em variadas ações em nível nacional usando os atributos da competência em informação.

\section{RELATO DE EXPERIÊNCIA}




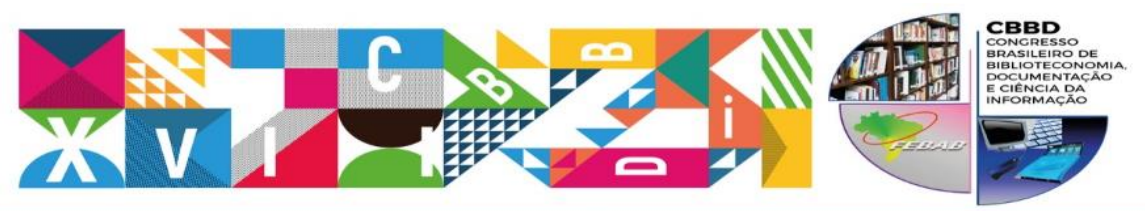

XXVII CONGRESSO BRASILEIRO DE BIBLIOTECONOMIA, DOCUMENTAÇÃO E CIÊNCIA DA INFORMAÇÃOO

TEMA CENTPAL: Objetivos para o Desenvolvimento Sustentável das Naçóes Unidas:
como as bibliotecas podem contribuir com a implementaçáo da Agenda 2030

Este trabalho tem como objetivo mostrar que os resultados obtidos através dos atributos da competência em informação aplicados às bibliotecas da Rede Ametista da CPRM estão de acordo com a missão da empresa para o desenvolvimento em soluções efetivas para o bem-estar da sociedade.

O relato de experiência apresenta as ações desenvolvidas nas bibliotecas da Rede Ametista, no período de 2014 à 2017, com base nas atividades de rotina e em exemplos de alguns resultados obtidos pelas bibliotecas. Essas atividades e exemplos foram registrados na Biblioteca Central, localizada no Rio de Janeiro, e na Biblioteca Regional de Fortaleza. Outras ações foram desenvolvidas ao longo do Programa como a elaboração de boletins informativos e o engajamento das bibliotecas no Projeto CPRM Sustentável.

Cabe ressaltar que o Programa de Competência em Informação teve ampla divulgação entre as bibliotecas regionais que fazem parte da Rede Ametista e contou com a colaboração de outros setores da instituição, tais como: Divisão de Recursos Humanos, Divisão de Editoração, Divisão de Marketing, Divisão de Informática e Assessoria de Comunicação.

\subsection{Metodologia das Ações}

O Programa de Competência em Informação foi idealizado em 5 (cinco) etapas denominadas Ações, com suas respectivas metodologias para a solução de problemas, que se sucediam à medida em que iam sendo realizadas, a partir de 2014.

As diretrizes do Quadro 1 foram realizadas na Biblioteca Central da CPRM, no Rio de Janeiro, e podem trazer contribuições para que outras bibliotecas e unidades de informação possam elaborar ou atualizar o seu próprio programa.

Quadro 1 - Ações realizadas na Biblioteca Central da CPRM. Rio de Janeiro, 2014 - 2015

\begin{tabular}{|l|l|l|l|l|l|}
\hline \multicolumn{1}{|c|}{ Elementos } & Ação 1 & Ação 2 & Ação 3 & Ação 4 & Ação 5 \\
\hline Ação & Visitas Guiadas & Atendimento & Treinamento & Palestrantes & Treinamento à \\
\hline
\end{tabular}



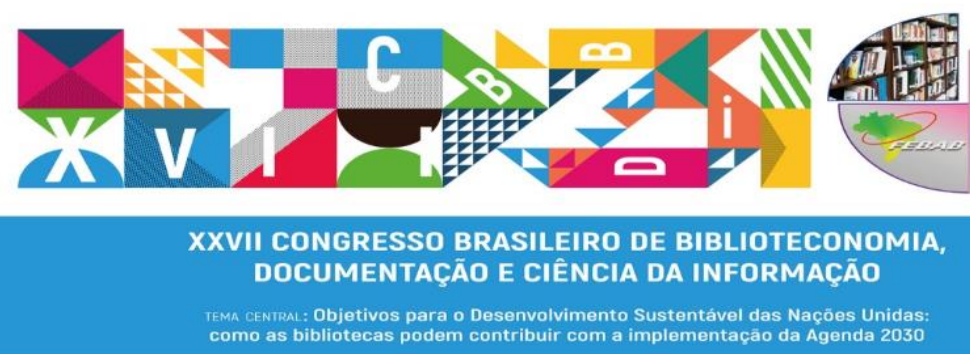

\begin{tabular}{|c|c|c|c|c|c|}
\hline & & Individual & $\begin{array}{l}\text { Presencial em } \\
\text { Grupos }\end{array}$ & Externos & Distância \\
\hline Público-Alvo & $\begin{array}{l}\text { Admitidos no } \\
\text { último concurso } \\
\text { público e } \\
\text { visitantes externos }\end{array}$ & $\begin{array}{l}\text { Pesquisadores } \\
\text { internos e externos }\end{array}$ & $\begin{array}{l}\text { Pesquisadores da } \\
\text { CPRM }\end{array}$ & $\begin{array}{l}\text { Todos os } \\
\text { funcionários da } \\
\text { CPRM }\end{array}$ & $\begin{array}{l}\text { Técnicos, Analistas } \\
\text { e Pesquisadores }\end{array}$ \\
\hline Objetivos & $\begin{array}{l}\text { Promover maior } \\
\text { utilização do } \\
\text { acervo da } \\
\text { Biblioteca e do } \\
\text { Multimeios } \\
\text { (acervo } \\
\text { fotocartográfico) }\end{array}$ & $\begin{array}{l}\text { Sanar dúvidas } \\
\text { específicas e } \\
\text { pontuais sobre as } \\
\text { ferramentas de } \\
\text { pesquisa nas bases } \\
\text { de dados } \\
\text { bibliográficas e } \\
\text { georreferenciadas } \\
\text { disponíveis na } \\
\text { CPRM }\end{array}$ & $\begin{array}{l}\text { Promover a } \\
\text { melhor utilização } \\
\text { das bases de } \\
\text { dados da CPRM: } \\
\text { Catálogo Online } \\
\text { PHL, Biblioteca } \\
\text { Virtual Acesso } \\
\text { Livre e } \\
\text { Repositório } \\
\text { Institucional } \\
\text { RIgeo }\end{array}$ & $\begin{array}{l}\text { Promover a } \\
\text { aquisição de } \\
\text { novos } \\
\text { conhecimentos }\end{array}$ & $\begin{array}{l}\text { Promover a } \\
\text { aquisição de novos } \\
\text { conhecimentos e } \\
\text { habilidades de } \\
\text { informação }\end{array}$ \\
\hline Metodologia & $\begin{array}{l}\text { Visitas em grupos } \\
\text { de no máximo } 10 \\
\text { (dez) } \\
\text { participantes. } \\
\text { Divulgação e } \\
\text { agendamento dos } \\
\text { participantes } \\
\text { foram realizados } \\
\text { pela Divisão de } \\
\text { Recursos } \\
\text { Humanos }\end{array}$ & $\begin{array}{l}\text { Atendimento } \\
\text { personalizado com } \\
\text { o horário agendado } \\
\text { e o espaço definido } \\
\text { pela Biblioteca }\end{array}$ & $\begin{array}{l}\text { Palestras } \\
\text { presenciais } \\
\text { ministradas pela } \\
\text { Equipe da } \\
\text { Biblioteca com o } \\
\text { objetivo de } \\
\text { transmitir } \\
\text { informações } \\
\text { claras e práticas }\end{array}$ & $\begin{array}{l}\text { Palestras } \\
\text { ministradas por } \\
\text { palestrantes } \\
\text { externos } \\
\text { realizadas na } \\
\text { CPRM, no Rio de } \\
\text { Janeiro, com } \\
\text { transmissão para } \\
\text { todas as suas } \\
\text { Unidades } \\
\text { Regionais através } \\
\text { de } \\
\text { videoconferência } \\
\end{array}$ & $\begin{array}{l}\text { Cursos de } \\
\text { Capacitação com } \\
\text { baixo custo de } \\
\text { implementação } \\
\text { realizados na } \\
\text { CPRM, no Rio de } \\
\text { Janeiro, com } \\
\text { transmissão para } \\
\text { todas as suas } \\
\text { Unidades Regionais } \\
\text { através de } \\
\text { videoconferência }\end{array}$ \\
\hline Data & $08 / 10 / 2014$ & $20 / 05 / 2015$ & $06 / 11 / 2014$ & $30 / 09 / 2015$ & $16 / 07 / 2014$ \\
\hline
\end{tabular}

Fonte: As autoras

O resultado de participação de usuários nestas Ações foi quantificado sendo esses dados mensurados por meio de estatísticas conforme o Quadro 2.

Quadro 2 - Participação nas Ações da Biblioteca Central da CPRM. RJ, 2014-2015

\begin{tabular}{|l|l|l|l|l|l|}
\hline Elementos & Ação 1 & Ação 2 & Ação 3 & Ação 4 & Ação 5 \\
\hline
\end{tabular}



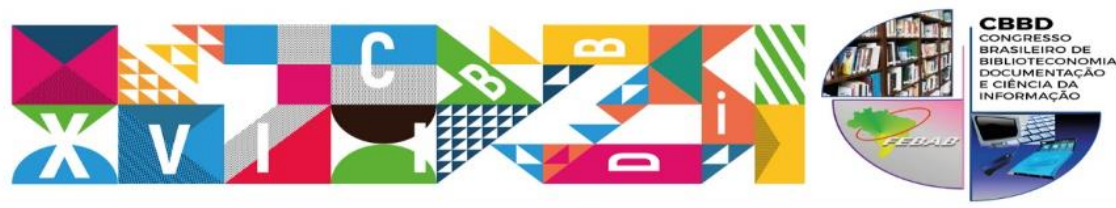

XXVII CONGRESSO BRASILEIRO DE BIBLIOTECONOMIA,

DOCUMENTAÇĀO E CIÊNCIA DA INFORMAÇĀO

TEMA ceNTRAl: Objetivos para o Desenvolvimento Sustentável das Naçōes Unidas:
como as bibliotecas podem contribuir com a implementação da Agenda 2030

\begin{tabular}{|c|c|c|c|c|c|}
\hline Ação & $\begin{array}{l}\text { Visitas Guiadas } \\
\text { na } \\
\text { Biblioteca, no } \\
\text { Multimeios e no } \\
\text { Museu Ciências } \\
\text { da Terra }\end{array}$ & $\begin{array}{l}\text { Atendimento } \\
\text { Individual em } \\
\text { Bases de Dados } \\
\text { da CPRM }\end{array}$ & $\begin{array}{l}\text { Treinamento } \\
\text { Presencial em } \\
\text { Grupos } \\
\text { em Bases de } \\
\text { Dados da } \\
\text { CPRM }\end{array}$ & $\begin{array}{l}\text { Palestrantes } \\
\text { Externos } \\
\text { Palestra Gestão do } \\
\text { Conhecimento }\end{array}$ & $\begin{array}{l}\text { Treinamento à } \\
\text { Distancia } \\
\text { Treinamento da } \\
\text { Base Elsevier }\end{array}$ \\
\hline Resultados & $\begin{array}{l}5 \text { Grupos - } \\
78 \text { Visitantes }\end{array}$ & 22 Usuários & $\begin{array}{l}3 \text { Grupos } \\
48 \text { Usuários }\end{array}$ & $\begin{array}{l}\text { 1 Palestra em } \\
\text { Videoconferência } \\
\text { para } 13 \text { Unidades } \\
\text { Regionais }\end{array}$ & $\begin{array}{l}1 \text { Treinamento em } \\
\text { Videoconferência } \\
\text { para } 13 \text { Unidades } \\
\text { Regionais }\end{array}$ \\
\hline
\end{tabular}

Fonte: As autoras

Após essas Ações, observou-se um aumento significativo na utilização dos espaços e dos serviços que a Biblioteca oferece, seja de maneira presencial ou virtual. Os resultados foram positivos obtendo receptividade dos usuários que também registraram seu nível de satisfação por meio de cartas de agradecimento.

\subsection{Estatísticas das Atividades em Videoconferência}

Em 2016 priorizou-se a apresentação de palestras e treinamentos através de videoconferência para as Unidades Regionais da CPRM. Foram realizadas as seguintes atividades à distância e apresentamos, a seguir, o seu respectivo quantitativo de participantes. Obteve-se um total de 256 participantes.

Apresentação do RIgeo e do Integrador de pesquisa de mapas e projetos da CPRM = 66;

Treinamento Geobank - Banco de dados geológicos da CPRM = 54;

Treinamento Mendeley - Gerenciador de referência bibliográfica = 27;

Treinamento da Base Science Direct - Elsevier $=109$. 


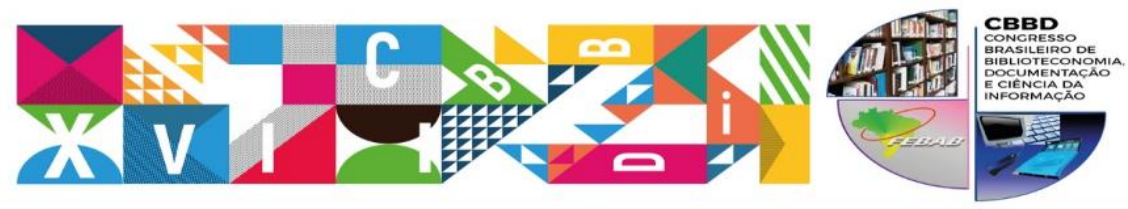

XXVII CONGRESSO BRASILEIRO DE BIBLIOTECONOMIA, DOCUMENTAÇÃO E CIÊNCIA DA INFORMAÇÃOO

TEMA CENTRAL: Objetivos para o Desenvolvimento Sustentável das Naçōes Unidas:
como as bibliotecas podem contribuir com a implementação da Agenda 2030

Apresentação do RIgeo e do Integrador de pesquisa de mapas e projetos da CPRM

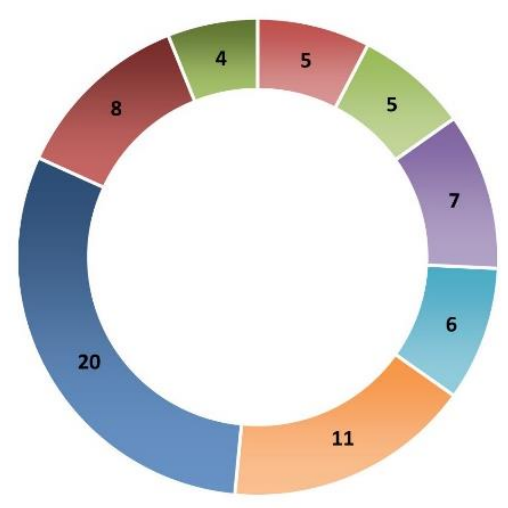

= Belém

- Fortaleza

n Porto Alegre

m Porto Velho

= Recife

- Rio de Janeiro

- Salvador

- São Paulo

Total $=66$ participantes

Treinamento do Mendeley - Gerenciador de referência bibliográfica

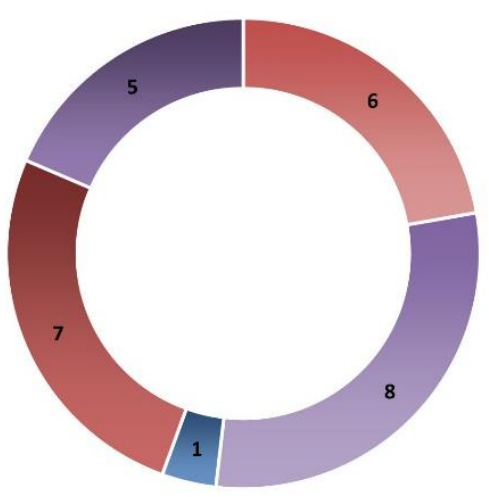

Total $=27$ participantes
Treinamento Geobank - Banco de dados geológicos da CPRM

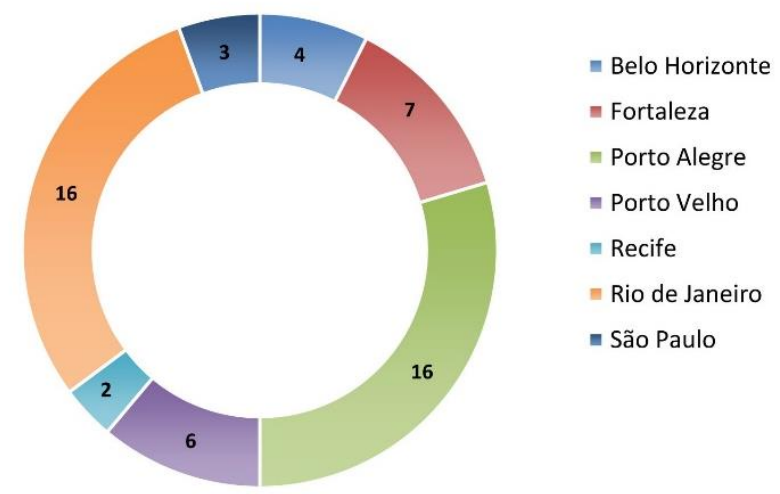

Total $=54$ participantes

Treinamento da Base ScienceDirect - Elsevier

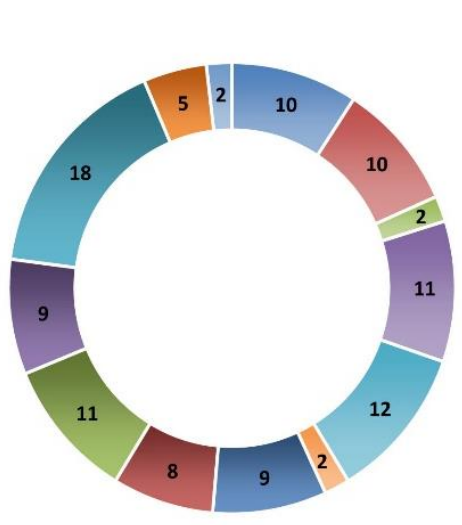

Total $=109$ participantes

$$
\begin{aligned}
& \text { = Belém } \\
& \text { = Belo Horizonte } \\
& \text { = Brasília } \\
& \text { = Fortaleza } \\
& \text { = Goiânia } \\
& \text { = Manaus } \\
& \text { = Porto Alegre } \\
& \text { - Porto Velho } \\
& \text { = Recife } \\
& \text { - Rio de Janeiro } \\
& \text { = Salvador } \\
& \text { = São Paulo } \\
& \text { = Teresina }
\end{aligned}
$$

Quantitativo total de participação em palestras e treinamentos em 2016

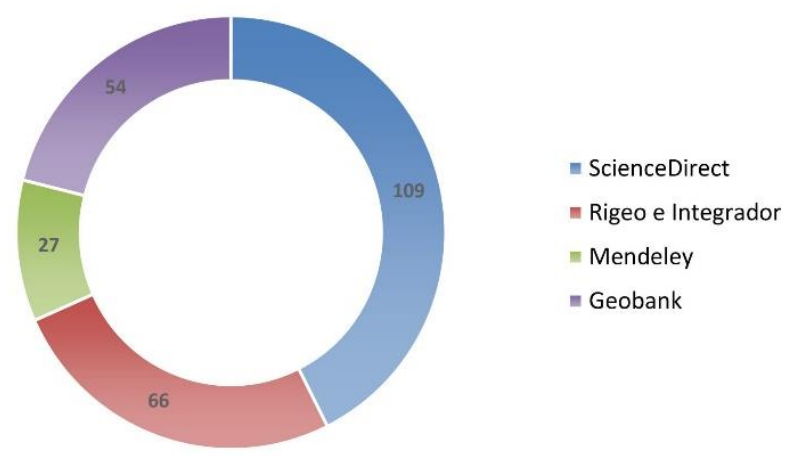




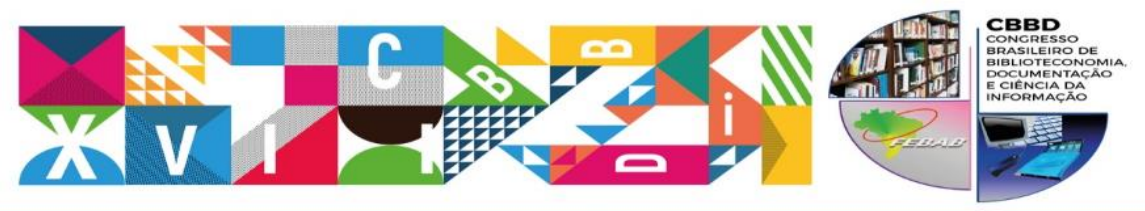

XXVII CONGRESSO BRASILEIRO DE BIBLIOTECONOMIA, DOCUMENTAÇÃO E CIÊNCIA DA INFORMAÇÃOO

TEMA CENTRAL: Objetivos para o Desenvolvimento Sustentével das Naçóes Unidas:
como as bibliotecas podem contribuir com a implementação da Agenda 2030

\section{DESENVOLVIMENTO SUSTENTÁVEL}

A Declaração de Lyon de agosto de 2014 sobre o Acesso à Informação e Desenvolvimento, preconiza que "o desenvolvimento sustentável visa garantir, a longo prazo, a prosperidade socioeconômica e o bem-estar das pessoas em todos os lugares".

Nessa Declaração, ela reconhece que "intermediários da informação, como bibliotecas, arquivos, organizações da sociedade civil, líderes comunitários e os meios de comunicação têm as habilidades e recursos para ajudar os governos, instituições e indivíduos para comunicar, organizar, estruturar e compreender os dados que são fundamentais para o desenvolvimento".

Essas instituições podem fazer isso "preservando e garantindo o acesso permanente ao patrimônio cultural, aos registros governamentais e às informações, por meio da gestão das bibliotecas e arquivos nacionais e outras instituições de patrimônio público".

Elas também podem participar "oferecendo treinamento e desenvolvendo habilidades para ajudar as pessoas a acessar e compreender as informações e os serviços mais úteis para elas".

E a Declaração de Lyon continua: "a pobreza é multidimensional e o progresso na erradicação da pobreza está vinculado ao desenvolvimento sustentável em diversas áreas”.

\subsection{Bibliotecas da CPRM e Desenvolvimento Sustentável}

Baseada nessa premissa, junto à missão da CPRM que é gerar e disseminar conhecimento geocientífico com excelência, contribuindo para a melhoria da qualidade de vida e do desenvolvimento sustentável do Brasil, a Rede Ametista de Bibliotecas da CPRM, além de promover palestras e treinamentos, também se engajaram no Projeto CPRM Sustentável.

A Biblioteca Central da CPRM e a Biblioteca Regional de Fortaleza participaram dessas ações. As bibliotecas coletaram livros e revistas para serem doados à instituições carentes.

A Biblioteca Regional de Fortaleza, através de sua bibliotecária responsável, coletou, inclusive, roupas para doação para instituições do Estado do Ceará. Esta ação teve ampla participação 


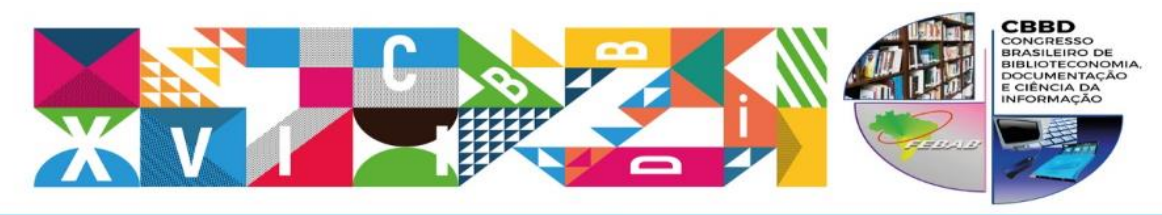

XXVII CONGRESSO BRASILEIRO DE BIBLIOTECONOMIA,

DOCUMENTAÇÃO E CIÊNCIA DA INFORMAÇÃOO

TeMA cenrpal: Objetivos para o Desenvolvimento Sustentável das Naçōes Unidas:
como as bibliotecas podem contribuir com a implementação da Agenda 2030

dos empregados da CPRM - Residência de Fortaleza.

A Biblioteca Regional de Fortaleza também participou em ações com a Associação de Empregados da CPRM - Residência de Fortaleza para a elaboração do boletim trimestral de título "InREFOrmativo" que comunica aos funcionários e aos que visitam a Biblioteca, dicas de sustentabilidade, entrevistas, eventos na instituição, eventos culturais em Fortaleza, ética na gestão pública, fotos dos locais com paisagens dos projetos realizados, novas aquisições da biblioteca e sugestões para leitura e filmes.

Os resultados dessas ações foram positivos para ambas as bibliotecas porque observou-se a participação da maioria dos empregados da CPRM que demonstrou satisfação com os novos serviços oferecidos através de elogios verbais.

\section{CONCLUSÕES}

Nesta construção objetivou-se esclarecer a estruturação de um Programa de Competência em Informação que, com o intuito de promover e disseminar o conhecimento geocientífico para seus usuários internos e externos por meio das unidades de informação, também contribui para a melhoria da qualidade de vida dos cidadãos e, consequentemente, para o desenvolvimento sustentável do Brasil. Observou-se nas 5 (cinco) Ações desenvolvidas para o Programa de Competência em Informação da Rede de Bibliotecas da CPRM que todas as Ações programadas dependem de fatores externos como: demanda de usuários, disponibilidade de palestrantes, temas de interesse da comunidade técnico-científica e compatibilização de agendas dos palestrantes e salas de videoconferência na CPRM. Observou-se também um aumento da demanda nas Bibliotecas. 0 nível de satisfação do usuário foi muito bom, registrado por meio de cartas de agradecimento e de elogios verbais. Conclui-se que o Programa deve continuar, sempre se aperfeiçoando, no seu propósito de colaborar na construção e na divulgação do conhecimento em Geociências para o bem-estar da sociedade brasileira. 


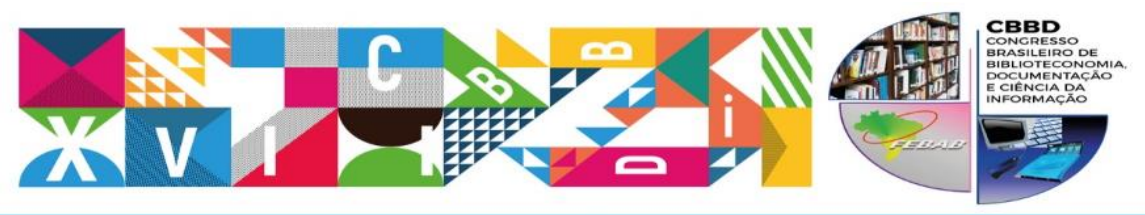

XXVII CONGRESSO BRASILEIRO DE BIBLIOTECONOMIA,

DOCUMENTAÇÃOO E CIÊNCIA DA INFORMAÇĀO

TEMA CENrRaA: Objetivos para o Desenvolvimento Sustentável das Naçōes Unidas:
como as bibliotecas podem contribuir com a implementaçao da Agenda 2030

\section{REFERÊNCIAS}

CPRM - SERVIÇO GEOLÓGICO DO BRASIL. Boas vindas do Diretor-Presidente. Disponível em:

<http://www.cprm.gov.br/publique/Sobre-a-CPRM-49>. Acesso em: 28 nov. 2017a.

Sobre [Rede de Bibliotecas - Rede Ametista]. Disponível em:

<http://www.cprm.gov.br/publique/Redes-Institucionais/Rede-de-Bibliotecas---Rede-Ametista/Sobre169>. Acesso em: 28 nov. 2017b.

DECLARAÇÃo de Lyon sobre o acesso à informação e desenvolvimento. Lyon: IFLA, 2014. 3p.

DUDZIAK, E. A. Information literacy: princípios, filosofia e prática. Ciência da Informação, Brasília, v. 32, n. 1, p. 23 - 35, jan./abr. 2003.

Faróis da Sociedade da Informação. National Forum on Information Literacy. Declaração de Alexandria sobre competência informacional e aprendizado ao longo da vida. Disponível em: $<$ https://www.ifla.org/files/assets/wsis/Documents/beaconinfsoc-pt.pdf>. Acesso em: 3 nov. 2017.

LAU, J. Diretrizes sobre desenvolvimento de habilidades de informação para a aprendizagem permanente. Disponível em: <http://www.febab.org.br/jesus_lau_trad_livro_comp_v_f.doc >. Acesso em: 16 abr. 2014.

SANTOS, E. M; DUARTE, E. A.; PRATA, N. V. Cidadania e trabalho na sociedade da informação: uma abordagem baseada na competência informacional.

Perspectivas em Ciência da Informação, v. 13, n. 3, p. 208 - 222, set./dez. 2008.

\section{Agradecimentos:}

Priscila Cristina de Faria Ururahy

Bibliotecária da CPRM - Serviço Geológico do Brasil da Biblioteca Central do Rio de Janeiro (RJ)

Teresa Cristina Sampaio Rosenhayme

Bibliotecária da CPRM - Serviço Geológico do Brasil da Biblioteca Central do Rio de Janeiro (RJ) 